(C)2009 IEEE. Personal use of this material is permitted. However, permission to reprint/republish this material for advertising or promotional purposes or for creating new collective works for resale or redistribution to servers or lists, or to reuse any copyrighted component of this work in other works must be obtained from the IEEE. 


\title{
What Educational Activities Fit Virtual Worlds: Towards a Theoretical Evaluation Framework
}

\author{
Bjorn Jaeger \\ Norwegian School of SCM and Logistics, Molde University College, Norway \\ School of Information Systems, Curtin Business School, Curtin University of Technology, Perth, Australia \\ bjorn.jager@himolde.no
}

\begin{abstract}
Many universities and colleges are investing in teaching and learning developments in virtual worlds despite a lack of any clear guidelines or rules for when virtual worlds will provide benefits over established communication media. Among activities that have been successfully tried out so far are interpersonal role play and oral language education, while other practices like traditional lecturing and business transaction oriented role plays seem to be less suitable for successful implementation. Our objective in this paper is to develop an evaluative framework educational for educational activities in virtual worlds based on Media Richness and Task Closure Theories from Management Information Systems. We demonstrate the use of the framework for three educational activities conducted in the virtual world of Second Life.
\end{abstract}

Index Terms-Virtual Worlds, e-learning, Media Richness Theory, Task Closure Theory, Evaluative Framework.

\section{InTRODUCTION}

A large number of universities around the world experiment with the use of virtual worlds for educational purposes. In a report series from UK on educational developments in Second Life they find that $75 \%$ of UK universities are active in Second Life [7]. The researchers Bowers, Ragas, and Neely [2] conducted a worldwide survey with 162 respondents in 25 academic disciplines from 15 countries on the satisfaction with using Second Life and whether the respondents intended to use Second Life again. The results showed a positive attitude towards both items. Research into the usage of $3 \mathrm{D}$ virtual worlds as an educational tool has to a large extent been explorative with discipline-specific qualitative case studies as is evident from conference proceedings and special issues of journals on this theme. There exists a large body of literature on the fit between task and medium in management science with major work being [13, $4,5,16]$, however these are all done before the current state of virtual worlds. Recently research including virtual worlds has started to appear most of which look at media selection for different tasks $[10,12,15]$. We are interested in the capabilities of the particular medium virtual worlds to support educational activities, i.e. we use previous theories as a reference to select educational activities for virtual worlds. Some theories like Media Richness Theory have previously been applied to distance education in relation to learning management tasks. In [11] the authors evaluate several technologies used in distance education. They find that the richer the media the grater the satisfaction since it enhance communication. Others have found situations where the oppos- ite is true. Alavi, Marakas and Yoo [1] found that more rich distance learning environments had lower learning outcomes than less rich environments when comparing e-mail and a sophisticated Group Support System. Zigurs and Buckland [16] developed a task-technology fit theory related to various e-collaboration tools. They classified business management tasks and e-collaboration tools into groups and studied how they match. However, none of these investigations included virtual worlds in its current state. Given the large number of universities exploring the use of virtual worlds in education we suggest that there is a need for a general theoretical framework that can be used to indicate what educational tasks that are likely to be successfully implemented in virtual worlds. Therefore our objective in this paper is to develop a Theoretical Evaluative Framework for assessment of how well a given educational task fits virtual worlds. The framework is based on Media Richness and Task Closure Theories from Management Information Systems, and Psychology Pedagogy. The remaining of this paper is organized as follows. Chapter II gives theoretical background. Chapter III presents the framework. In Chapter IV we give an example on the use of the framework to evaluate three educational activities in the virtual world of Second Life. Chapter V provides conclusions.

\section{Theoretical BaCkground}

The recent development of new communication media like virtual worlds have provided a set of new features that are likely to be useful for educational situations in general, and for distributed education in particular. Previous research in Information Systems has focused on the fit between the task and the medium and the social environment $[13,4,5]$. We build our framework on these theories. Note that we assume that the tasks to be evaluated are conducted according to principles by which learning is ruled. This relates the framework to the context of the learning ecosystem in the sense that the framework follows ecological principles by which task-medium fit are ruled.

\section{A. Media Richness Theory}

The researchers Daft and Lengel and followers proposed Media Richness Theory to describe the fit between the media and the task in business management communication [4, 5]. Media Richness Theory has been successfully used to describe the suitability of a medium to communicate certain tasks. The main assumptions of Media Richness Theory are 
that individuals, groups, and organizations process information to reduce uncertainty and unequivocality and that some communication media are more suitable for certain tasks than other. Uncertainty is the difference between the amount of information required to perform the task and the amount of information already possessed. Equivocality is defined as the ambiguity inherent in the task caused by conflicting and inconsistent interpretations and expectations. Media Richness Theory defines the richness of a medium as being characterized by the four properties I-IV: I) Capability to provide Instant Feedback: this allows communicators to ask questions and for corrections to be made facilitating fast convergence on a common interpretation. II) Capability to Convey Multiple Cues: characterize the number and types of cues that can be part of a communication, like variation in voice, body gestures, physical appearance, sounds, text, numbers, and graphical symbols. Cues can steer participants towards issues that help to make real progress and away from distraction cues. Cues can inform the learner where he/ she is in the process i.e. what has been delivered and what remains. III) Capability of Language Variety: is the range of meaning that can be conveyed by language. The use of numbers and formulas provide greater precision, but natural language conveys a broader set of concepts and ideas. This can also be denoted as multiplicity of communication forms, e.g. e-mail, instant messages, collaborative writing, voice chat, etc. $I V)$ Capability to provide personal focus: this reflects the ability of the medium to convey emotions and feelings of the communicators. It also encompasses the tailoring capabilities of the medium to satisfy specific perspectives of the receiver.

According to the above characteristics I-IV, Media Richness Theory classify the communication media in order of decreasing richness; face-to-face, video, voice, written, addressed documents, documents, unaddressed documents. Face-to-face is considered the richest medium because it provides instant feedback and multiple cues via body language, tone of voice, smell, visual look, temperature and other physical real world cues. Video rank below face-toface since it allows body language and verbal cues such as words, intonation, and silence, but it cannot convey smell, temperature and the same level of group communication

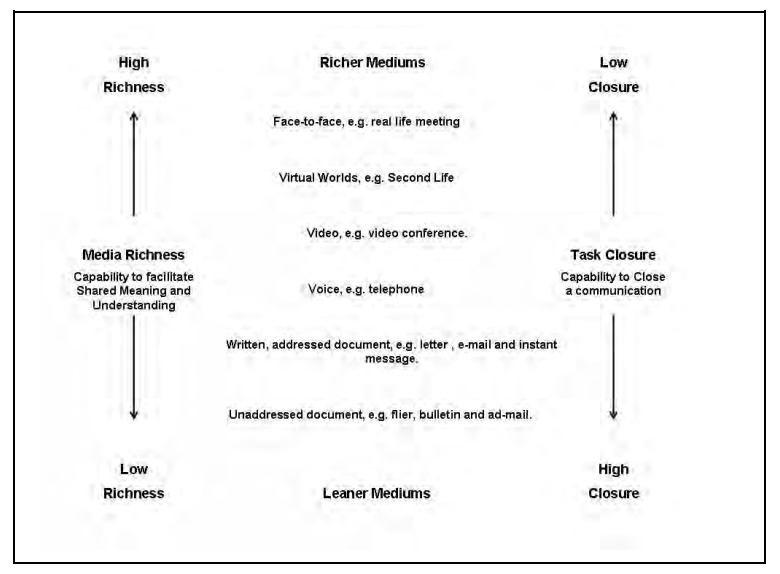

Fig. 1 Classification of media types possibilities as face-to-face. At the lowest richness level is unaddressed impersonal documents typically mass distributed. Other media can be classified in a similar way, we have arguably included Virtual Worlds by ranking it below face-to-face but above video. This is because Virtual Worlds lacks real life cues such as smell but since it support real time video it includes all video capabilities in addition to other virtual world features. We note that for some features Virtual Worlds even goes beyond what is possible in real life face-to-face environments, like avatar flying or near instant transportation to other virtual locations. A given media can be classified as being a high information richness media (high richness media) or a low information richness media (low richness media) as illustrated in Fig. 1.

\section{B. Task Closure Theory}

Task Closure Theory postulates that the ability to effectively complete a communication or close a task is a key driver for an individual's media preference [13]. Investigations leading to the theory found that after completing a communication individuals felt they have discharged their responsibility to communicate and they were left with a sense of completeness. The theory indicates that enhanced ability to achieve closure will lead to lowered task fragmentation and reduced stress. An example of closure being achieved is when sending off an e-mail to inform recipients of a regular event like a meeting. Task Closure Theory is based on the interaction between the Recipient Availability and Social Presence. Recipient Availability indicates if the recipient is currently available or available at a later point in time. Social Presence indicates the extent to which a communicator needs partners to get a feeling of being psychologically present. Asynchronous electronic media, e.g. e-mail, is classified as High Closure Media while rich media like face-to-face is classified as Low Closure Media as illustrated in Fig. 1.

\section{Media Richness Theory and Task Closure Theory}

Rich media is classified as being High Richness and Low Closure Media. This means they support the same type of tasks, tasks typically including development of shared meaning or common understanding. Likewise, Low Richness and High Closure Media support the same type of tasks, for example messages with numeric content that is part of a sales process, like delivery date. The combinations of media types according the two theories are illustrated in Fig. 1.

\section{Delayed Feedback}

Feedback is central to teaching and learning. We recognize this by including Delayed Feedback as an additional factor in the framework. Delayed Feedback is based on recorded communications. Virtual Worlds has the intrinsic property of mediated technologies that they can be recorded, stored, and played back with little effort at low costs. Recording is not an option in the Second Life client, but one can use one of the commonly available recording tools such as Camtasia or Fraps who records activities including sound 
into a movie file. Recording and playback enables post-exercise reflection and a debriefing of the experiences which is important for the learning outcome [6].

\section{Theoretical Evaluation Framework}

We want to find the potential for various educational activities to be successfully implemented in virtual worlds. To do this, we specify what needs the educational activity has in order to be conducted properly on one hand, and on the other hand we describe the capabilities provided by the Virtual World. To indicate the goodness of the fit between activity needs and virtual world capabilities for each factor found in the previous section we develop an Activity-Capability Indicator (ACI) which is a number between 0 and 1 computed by weighting a Need Indicator (NI) and a Capability Indicator (CI) to each other. NI indicates how important the factor is for the educational activity. E.g. the need for instant feedback in a negotiation role play is high and set to 0.9 . Likewise CI indicates the capability of the virtual world to support a factor. E.g. the capability of a virtual world to provide instant feedback is medium high as justified below therefore $\mathrm{CI}$ is set to 0.6. This gives ACI equal to $0.9 * 0.6=0.54$. An ACI equal or close to 1 signals a very good fit while a factor equal or close to 0 indicates a bad fit. The average of all ACI's gives the potential for a specific educational activity to be successfully implemented in virtual worlds; we call this the Potential Indicator (PI). Since it is not possible to estimate NI or CI precisely due to the complexity of the tasks and the medium, and since we by weighting the factors to each other get a lower combined value than each factor we use the following coarse scale for

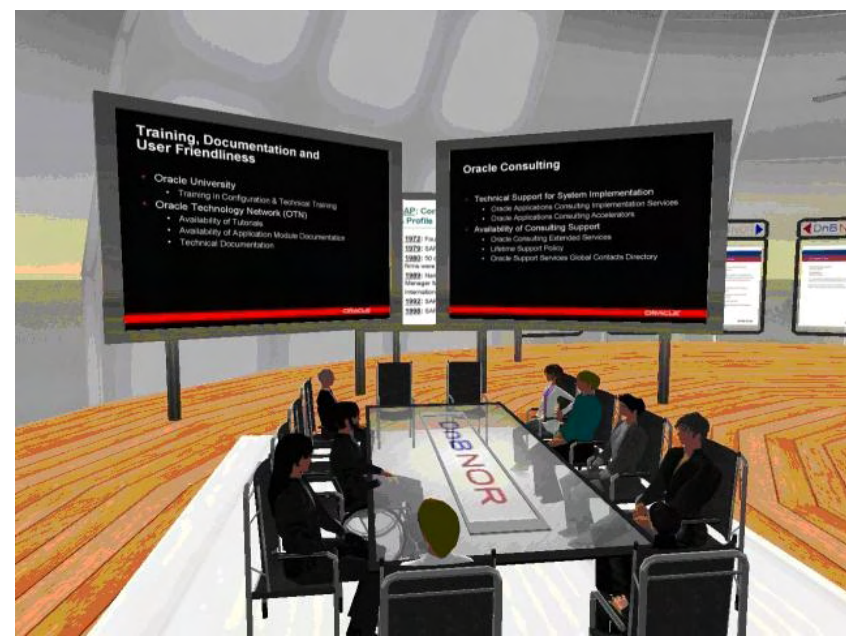

Fig.2 Role play in Second Life. Buyer team is at the right hand side and the current vendor team is at the left hand side with guest experts from business at the end of the table.

\begin{tabular}{|c|l|c|c|c|}
\hline & \multicolumn{1}{|c|}{ Factor } & $N I$ & $C I$ & $A C I$ \\
\hline 1 & Instant Feedback & {$[0,1]$} & {$[0,1]$} & $\mathrm{NI}^{*} \mathrm{CI}$ \\
\hline 2 & Delayed Feedback & {$[0,1]$} & {$[0,1]$} & $\mathrm{NI}^{*} \mathrm{CI}$ \\
\hline 3 & Multiplicity of Cues & {$[0,1]$} & {$[0,1]$} & $\mathrm{NI}^{*} \mathrm{CI}$ \\
\hline 4 & Language variety & {$[0,1]$} & {$[0,1]$} & $\mathrm{NI}^{*} \mathrm{CI}$ \\
\hline 5 & Personal focus & {$[0,1]$} & {$[0,1]$} & $\mathrm{NI}^{*} \mathrm{CI}$ \\
\hline 6 & Low Task Closure & {$[0,1]$} & {$[0,1]$} & $\mathrm{NI}^{*} \mathrm{CI}$ \\
\hline \multicolumn{4}{|r|}{} & $P I$ \\
\hline
\end{tabular}

Table 1 Evaluative Framework Factors and Indicators. PI is the average of the six ACIs

the combined ACI: An activity with VW-Potential in the interval $[0,0.3>$ is considered to have low potential for successful implementation in virtual worlds, [0.3-0.5> medium potential and [0.5-1] has high potential for successful implementation. The factors and their value range are summarized in Table 1.

\section{Evaluation of Educational Activities}

This evaluation is based on some of the educational activities conducted in the Kamimo Virtual Campus project 2007-2008 [3, 9] funded by the Norwegian Open University (Norgesuniversitetet). The project which was collaboration between University of Kalmar, Sweden, University of Central Missouri, USA and Molde University College, Norway established two islands in Second Life; The Kamimo Island and the Virtual Montmartre Island. The Kamimo Island is a traditional campus environment with auditoriums, classrooms, and meeting places for smaller groups to be used to test various educational activities in Second Life. The Virtual Montmartre Island took another approach by making a replica of Montmartre, Paris in the post World War 1 area in the 1930s. In the remaining we look at some of the activities performed at the Kamimo Island. Second Life was selected for the project since it has become the de facto virtual world for educational activities. A given Virtual World like Second Life offers a set of capabilities at a given point of time, naturally these capabilities evolve as time pass on. For example, voice chat was introduced in Second Life viewer version 1.18.1.2 released August 2, 2007, a capability that has greatly enhanced learning and teaching possibilities in Second Life. An example of a capability that is currently missing in Second Life is a collaborative writing tool. We illustrate the use of the framework by looking at the current capabilities of Second Life.

\section{A. Selected Educational Activities}

To test the framework we select three of the activities performed in the Kamimo project; a) Interpersonal Role Play, b) Breaking into conversations and c) Traditional Lecturing. These were selected partly because we see the two first as successful implementations, while the last have not been successful in its current implementation. We acknowledge that our informal pre-judgement and opinion of the cases might bias the theoretical evaluation, but since the focus of this work is to develop the framework as such we use the activities we are familiar with to loosely verify the usability of the framework. 
a) Interpersonal Role Play: We have been running a role play on making high-level purchasing decisions for a company that consider buying an Enterprise Resource Planning (ERP) system to integrate their fragmented business processes and reduce transaction costs. ERP-systems are large and costly and effect the whole organization which typically must be reorganized to fit the system. Since such an investment often is the single largest investment a company does the procurement process is important. In real life much effort is put into selecting the best system for a company. In order to introduce the students to both the procurement process itself and characteristics of ERP-Systems we have used the role play "Response to Request-For-Proposal for an ERP-system" which is much used in Business and Management Information Systems classes [14]. The students are divided in four teams Wingate Inc. (Buyer), Oracle (Vendor), Microsoft (Vendor) and SAP (Vendor). The Wingate team is given a set of selection criteria and a scoring method to evaluate the three offers. The vendor teams are gives pointers to sales material from which they make sales presentations explaining how they will satisfy the request for a new system. See [14] for details. Traditionally this role play has been run in a classroom with some students participating in the play while the remaining students observe the activities. This environment is far from the high end business meeting rooms typically used in real life procurement negotiations of this kind. Thus, we decided to run the role play in Second Life. Using mediated communication for this type of negotiations puts strong requirements on the medium, especially so since in practice purchasing decisions are made based on both explicit and tacit knowledge. The researchers Giunipero, Dawley and Anthony [17] found that approximately equal amounts of formal data and tacit knowledge were used in buying decisions made by purchasing managers. Tacit knowledge relates to personal experiences, it represents knowledge that is used in evaluation, points of view, commitments and decisions. This type of knowledge is difficult to articulate or codify. In contrast, explicit knowledge is

\begin{tabular}{|l|l|l|}
\hline \multicolumn{1}{|c|}{ Factor } & \multicolumn{1}{|c|}{ Justification } & \multicolumn{1}{c|}{$A C I=N I^{*} C I$} \\
\hline $\begin{array}{l}\text { Instant Feed- } \\
\text { back }\end{array}$ & $\begin{array}{l}\mathrm{NI}=1, \text { since training } \\
\text { require immediate } \\
\text { feedback. }\end{array}$ & $\begin{array}{l}\mathrm{ACI}=1^{*} 0.6= \\
0.6\end{array}$ \\
\hline $\begin{array}{l}\text { Delayed } \\
\text { Feedback }\end{array}$ & $\begin{array}{l}\mathrm{NI}=0.7, \text { is useful to } \\
\text { learn from own previ- } \\
\text { ous behavior or of } \\
\text { others. }\end{array}$ & $\begin{array}{l}\mathrm{ACI}=0.7 * 0.9= \\
0.63\end{array}$ \\
\hline $\begin{array}{l}\text { Multiplicity } \\
\text { of Cues }\end{array}$ & $\begin{array}{l}\mathrm{NI}=0.5, \text { mainly one } \\
\text { communication form }\end{array}$ & $\begin{array}{l}\mathrm{ACI}=0.5 * 0.7= \\
\text { (voice) }\end{array}$ \\
\hline $\begin{array}{l}\text { Language } \\
\text { variety }\end{array}$ & $\begin{array}{l}\mathrm{NI}=0.2 \text { since we rely } \\
\text { mostly on voice }\end{array}$ & $\mathrm{ACI}=0.2 * 0.7=$ \\
\hline $\begin{array}{l}\text { Personal fo- } \\
\text { cus }\end{array}$ & $\begin{array}{l}\mathrm{NI}=0.8, \text { need to con- } \\
\text { vey personal feelings }\end{array}$ & $\begin{array}{l}\mathrm{ACI}=0.8 * 0.7= \\
0.56\end{array}$ \\
\hline $\begin{array}{l}\text { Low Task } \\
\text { Closure }\end{array}$ & $\begin{array}{l}\mathrm{NI}=0.8, \text { the situation } \\
\text { does not call for a spe- }\end{array}$ & $\mathrm{ACI}=0.8^{*} 0.8=$ \\
& 0.64 \\
\hline & cific termination. & $\mathrm{PI}=0.49 \approx 0.5$ \\
\hline
\end{tabular}

Table 2 PI estimate for the "Breaking into conversation" activity knowledge that can be codified, but this only takes a purchase manager half the way to make a decision. Since our facilities in Second Life at the Kamimo Island are traditional campus facilities, we borrowed a business meeting room in Second Life from the island of the largest financial company in Norway (DnB NOR). A screenshot of a meeting is shown in Fig. 2.

b) Breaking into conversations: David Richardson from University of Kalmar was the first to start using Kamimo to teach a regular course completely in Second Life. The course is "Oral Production" which is an English language course of 3 ECTS credits [3]. As a teacher with yearlong extensive experience is using various distance educational tools Richardson in particular found Second Life to support affective elements better than other media. In the course he use a range of educational activities including: buddy groups, companion lead travelling to other locations in Second Life, peer-to-peer practicing on "Level of Formality" and "Active Listening", group practicing on "Breaking into conversations" and "Making good Presentations", and a Conflict Role Play. Another element is the "What you said" section in which he gives post lecture feedback on "What you said" with a companion "What you should have said". We choose to use the "Breaking into conversations" activity for our evaluation. This is about how to interrupt people in a polite way. The main technique used is having a buddy group sitting around a campfire discussing a topic when another buddy group break into their conversation in a polite way. Feedback is given by the teacher and the other group members.

c) Traditional Lecturing: Several teachers have used Kamimo for traditional lectures as a part of their course, courses include: Information Assurance, Enterprise Resource Planning with SAP, Purchase Management, Oral Production, Literature Composition and 3D design.

Teachers are displaying slides and presenting the material for the students who are listening and taking notes. The activity emphasizes the presentation as the technique for knowledge transfer. It is classified as a passive learning method since there is little or no interaction between students and the teacher or between students themselves.

\section{B. Evaluation}

Now the 6 factors in Table 1 are used to evaluate the three activities.

a) Interpersonal Role Play: Factor 1) Instant Feedback: The need for instant feedback in procurement negotiations is very high since the decision is to a large extent based on tacit information, thus we set the need indicator NI to 1 . The virtual environment supports instant feedback from other avatars by their voice and gestures, and possibly from other constructs like display screens. However since facial expressions, smell and other cues are lacking, we set the Capability Indicator CI to 0.6, giving an Activity-Capability Indicator ACI of $(1 * 0.6)=0.6$ for Instant Feedback.

Factor 2) Delayed Feedback: The need for delayed feedback is high. As an example consider the debriefing situation after all teams have presented their proposal when the 
buying team is going through their evaluations and scoring cards before announcing the winner. However, since an individual sales team has not seen the performance of the other sales teams, they might be puzzled by the decision of the buying team. In order to analyze the arguments leading to the conclusion the recording can be replayed and commented on by the teacher, the students and eventually external experts. One can also compare results across courses or semester based on the recordings. The situation does not depend on recordings since running the play in itself create a good learning experience [9]. Consequently we consider the need for delayed feedback for educational purposes to be high, setting NI to 0.7 . In practice it is relatively easy to do recordings. A complicating factor is that the recording computer typically is used by an avatar in the role play. In this situation one must use a sound card with two channels or one can use two sound cards in order to both record the sound and participate in the role play. Since software for doing this is free, e.g. Fraps the Capability Indicator CI is set to 0.9 giving an ACI equal to 0.63 for Delayed Feedback.

Factor 3) Multiplicity of Cues: As mentioned above it has been found that a sales manager base his decisions on approximately equal parts of tacit knowledge and concrete information. Since concrete information can easily be displayed or distributed the challenge is to convey tacit knowledge and the need for this is high so NI is set to 0.9. Concrete information can be communicated in Second Life by Notecards and Textures to be displayed on screens but this is very limited capabilities compared to standard web tools. The capability to convey information related to tacit knowledge comes from avatar behaviour, appearance and voice which has been found help in creating realistic role plays by Jones [8]. The negotiation is also believed to benefit from visual cues by using a professional looking meeting room, and cues can be used to guide the player in action (purchaser or vendor) on where he/she is in the process. Having all participants looking at the same environment makes the social structure of who is who clear, which is often hard in multiparty videoconferences. The Capability Indicator is set

\begin{tabular}{|c|c|c|}
\hline Factor & Justification & $A C I=N I^{*} C I$ \\
\hline $\begin{array}{l}\text { Instant Feed- } \\
\text { back }\end{array}$ & $\begin{array}{l}\mathrm{NI}=0.1 \text {, since this is } \\
\text { passive learning. }\end{array}$ & $\begin{array}{l}\mathrm{ACI}=0.1 * 0.6= \\
0.06\end{array}$ \\
\hline $\begin{array}{l}\text { Delayed } \\
\text { Feedback }\end{array}$ & $\begin{array}{l}\mathrm{NI}=0.5 \text {, repetition en- } \\
\text { hance learning. }\end{array}$ & $\begin{array}{l}\mathrm{ACI}=0.5 * 0.9= \\
0.45\end{array}$ \\
\hline $\begin{array}{l}\text { Multiplicity } \\
\text { of Cues }\end{array}$ & $\mathrm{NI}=0.2$, few needed. & $\begin{array}{l}\mathrm{ACI}=0.2 * 0.7= \\
0.14\end{array}$ \\
\hline $\begin{array}{l}\text { Language } \\
\text { variety }\end{array}$ & $\begin{array}{l}\mathrm{NI}=0.2, \text { teacher talks } \\
\text { to the students }\end{array}$ & $\begin{array}{l}\mathrm{ACI}=0.2 * 0.7= \\
0.14\end{array}$ \\
\hline $\begin{array}{l}\text { Personal fo- } \\
\text { cus }\end{array}$ & $\begin{array}{l}\mathrm{NI}=0.2 \text { since need to } \\
\text { convey personal feel- } \\
\text { ings in large group } \\
\text { settings is low }\end{array}$ & $\begin{array}{l}\mathrm{ACI}=0.2 * 0.7= \\
0.14\end{array}$ \\
\hline \multirow[t]{2}{*}{$\begin{array}{ll}\text { Low } & \text { Task } \\
\text { Closure } & \end{array}$} & $\begin{array}{l}\mathrm{NI}=0.6 \text {, a lecture ter- } \\
\text { minates at specific } \\
\text { time. }\end{array}$ & $\begin{array}{l}\mathrm{ACI}=0.6 * 0.8= \\
0.48\end{array}$ \\
\hline & & $\mathrm{PI}=0.24 \approx 0.2$ \\
\hline
\end{tabular}

Table 3: PI estimate for the "Traditional Lecturing" activity to 0.7 . ACI is then 0.63 for Multiplicity of Cues.

Factor 4) Language Variety: The need to use various communication forms like e-mail, instant messages in these negotiations are considered low since the interpersonal role play primarily rely on voice and the avatar interaction in the common meeting room. NI $=0.4$. Second Life has capability to support various communication forms including IM, public voice chat and group voice chat, but it lacks e-mail or a seamless integration with other forms giving a CI equal to 0.7 and ACI becomes 0.28.

Factor 5) Personal Focus: In negotiations there is a need for communicators to let personal feelings and emotions infuse the communication since this is part of tacit knowledge, thus we set NI to 0.8 . Second Life's capabilities to convey personal focus in this sense is mostly through voice intonations and avatar behaviour and appearance. Second Life currently lacks some capabilities like real-life face expressions and body language, thus $\mathrm{CI}$ is set to 0.7 . ACI becomes 0.56 .

Factor 6) Low Task Closure: The need for Task Closure is low since this is a negotiation with no strict requirement of when to stop. Thus we set the Need Indicator NI to a high value in order to be on the same scale as the other factors: NI is set to 0.8 . Second Life can be said to have low capability for task closure since it contains many distracting cues so we also rate the Capability Indicator CI to 0.8 . The ACI becomes 0.64 for Low Task Closure.

Now we can find the potential for successful implementation of activity a) Interpersonal Role Play by computing the average of all ACIs: Potential Indicator $(\mathrm{PI})=0.56 \approx$ 0.6 . A value of 0.6 indicates a high potential for successful implementation of the interpersonal role play in Second life.

b) Breaking into conversations: The capabilities (CI's) of Second Life for each factor are as in the role play case above, thus for this activity we decide the Need Indicators, NIs, for this activity. Since the way of reasoning follows the way we did it for the role play we summarize the evaluations in Table 2. We find a medium to high potential for successful implementation of the "Breaking in to a conversation" activity in Second life.

c) Traditional Lecturing: We decide the Need Indicators, NIs, for this activity in Table 3 . We find that there is a low potential for successful implementation of the "Traditional Lecturing" activity in Second life.

\section{Conclusions}

We have developed a theoretical framework for evaluating how likely it is for an educational activity to be successfully implemented in virtual worlds. The framework is based on Media Richness Theory, Task Closure Theory and Psychology Pedagogy. By using the framework we found that the educational activities "Interpersonal Role Play" and "Breaking into conversations" have high potential for successful implementation and that "Traditional Lecturing" has low potential for successful implementation in the current version of Second Life. This is in accordance with our expectations and experiences from using Second Life in the 
Kamimo Virtual Campus project and thus gives an initial verification of the framework. Our future work is to apply the framework to more educational activities and to further refine factors and numerical indicators in order to improve the framework.

\section{REFERENCES}

[1] Alavi, M., Marakas, G.M. and Yoo, Y. (2002) "A Comparative Study of Distributed Learning Environments on Learning Outcomes," Information Systems Research, Vol. 13, No. 4, December, 2002, pp. 404-415.

[2] Bowers, W., Ragas, M. and Neely, J. (2008). "Assessing the Value of Virtual Worlds for Post-Secondary Instructors: A Survey of Innovators, Early Adopters and the Early Majority in Second Life,". University of Florida, College of Journalism and Communications. 2008.

[3] Creelman, A., Richardson, D. and Petrakou, A. (2008). "Teaching and learning in Second Life - experience from the Kamimo project," Online Information Conference, 2-4 December, London, UK, 2008.

[4] Daft, R.L., and Lengel, R.H. (1984). "Information richness: a new approach to managerial behavior and organizational design". Cummings, L.L. \& Staw, B.M. (Eds.), Research in organizational behavior 6, (191-233). Homewood, IL: JAI Press.

[5] Daft, R.L., Lengel, R.H., and Trevino, L.K. (1987). "Message Equivocality, Media Selection, and Manager Performance: Implications for Information Systems". MIS Quarterly, Vol. 11, No. 3, September 1987, 355-366.

[6] De Freitas, S. (2006) Learning in Immersive worlds. Joint Information Systems Committee (JISC) e-Learning Programme, UK.
[7] Eduserv. (2008). "The Autumn 2008 Snapshot of UK Higher and Further Education Developments in Second Life,"

[8] Jones, S. (2007). "Adding value to online role plays: Virtual situated learning environments", Proceedings of Ascilite, Singapore 2007.

[9] Jæger, B., and Helgheim, B. (2008). "Results from a Role Play Exercise in Second Life for LOG505 and BØK700," Working Paper/Arbeidsnotat 2008:11, Molde University College, Norway

[10] Kim, H. M., Lyons, K., and Cunningham, M.A. (2008). "Towards a Framework for Evaluating Immersive Business Models: Evaluating Service Innovations in Second Life", Proceedings of the 41st Hawaii International Conference on System Sciences - 7-10 Jan. 2008.

[11] Martz, W.B. and Reddy, V. K. (2005). "Looking for Indicators of Media Richness Theory in Distance Education," Proceedings of the 38th Hawaii International Conference on System Sciences.

[12] Rice, R. E., Hart, P. J., Torobin, J., Shook, D., Tyler, J. E. and Ruchinskas, J. (1992) "Task Analyzability, Use of New Media, and Effectiveness: A Multi-Site Exploration of Media Richness," Organization Science, vol. 3, no. 4, pp. 475-500, 1992.

[13] Straub, D. and Karahanna, E. (1998). "Knowledge Worker Communications and Recipient Availability: Toward a Task Closure Explanation of Media Choice," Organization Science (9:2, March-April), 1998, pp. 160-175.

[14] M. Sumner, Enterprise Resource Planning, Prentice Hall, 2004. 185 pages.

[15] Sun, P-C and Cheng, H. C. (2007) "The design of instructional multimedia in e-Learning: A Media Richness Theory-based approach," Computers \& Education 49 (2007) 662-676.

[16] Zigurs, I., and Buckland, B. K. (1998). "A theory of task/technology fit and group support systems effectiveness," MIS Quarterly. v22 n.3. p. 313-334.

[17] Giunipero, L., Dawley, D., and Anthony W. P. (1999). "The Impact of Tacit Knowledge on Purchasing Decisions," The Journal of Supply Chain Management, vol.35, no. 1, pp. 42-49, 1999. 